\title{
Research on Financing Difficulties and Countermeasures of Small and Micro-Enterprises in China: An Analysis Based on COVID-19
}

\author{
Huixiang Wang ${ }^{1}$ and Hui $\mathrm{Xu}^{1,2, *}$ \\ ${ }^{1}$ School of Economics and Management, Yangtze University, Jingzhou, Hubei 434023, China \\ ${ }^{2}$ Hubei Rural Development Research Center, Jingzhou, Hubei 434023, China \\ *Corresponding author. Email: $201971001 @ y a n g t z e u . e d u . c n$
}

\begin{abstract}
This paper focuses on the current financing status of Chinese small and micro-enterprises under the epidemic situation of COVID-19 in early 2020 and explores the causes and recommendations from different perspectives. Using survey data from these enterprises, and observing the changes in financing sources of $\mathrm{HB}$ Trading Company before and after the epidemic, we find that although the epidemic has increased financing difficulties of enterprises, it was not the primary cause. The financing problems are caused by the imperfect credit systems of enterprises, the inadequate financial service systems and cumbersome approval procedures of government and the exclusive finance of financial institutions. Therefore, the paper makes targeted policy countermeasures from three different aspects, first of all, the small and micro-enterprises should establish their own brands, and improve management and credit systems, and then the government ought to improve the financial service systems and increase policy supports; in addition, the financial institutions should establish two-way information disclosure mechanisms and innovate financing methods.

Keywords: the small and micro-enterprises, the epidemic situation of COVID-19, financing difficulties,
\end{abstract}

countermeasures, China

\section{INTRODUCTION}

Small and micro-enterprises are collective terms for small, micro and family-run enterprises, and although individual enterprise is small and weak, relevant data shows that as many as 360,000 enterprises will form a huge synergy and become a mainstay in Chinese economic development. Their contributions to the national economy are mainly reflected in the following four dimensions (Ayyagari, Beck and Demirguc-Kunt, 2007) [1]. First, large numbers of enterprises include all aspects of people's livelihood, which maintain normal life of the residents and the operation of economy. Second, they play a significant role in GDP and taxation. In the third dimension, they provide abundant jobs, which meet nearly half of Chinese job-seeking needs. Finally, the enterprises are gradually becoming powerhouse in the construction of real economy with their huge fixed assets ratio. Financial supports are needed for continuing operations of small and micro-enterprises, which are important for them to expand the scales of production, and to transform their industrial structures. However, due to weak risk-resistance and single mode of production, enterprises are not priority targets for financial institutions in financing activities (Cull and $\mathrm{Xu}, 2005$; Sulong, Sulaiman, and Norhayati, 2015) [2-3]. The Chinese government has taken many measures to alleviate the financing difficulties of small and micro-enterprises. For example, the People's Bank and other departments jointly issued the Opinions on Further Promoting Financial Services for Small and Micro-Enterprises in 2018. Besides, the Chinese government has further strengthened inclusive financial support measures for small and micro-enterprises as a response to the impact of the epidemic since 2019. However, these policies only alleviated the financing difficulties to a certain extent. In short, solving the financing difficulties is the core of enterprises' development. In short, solving the financing difficulties is the core of enterprises' development.

Therefore, the significances of this selected study are as follows. On the one hand, through comprehensive reforms, the entire small and micro-financial market can be cleaned up. And the measures will ultimately deepen the credit contractual relationship between small and micro-enterprises and financial institutions, which also comply with the support requirements of the government's financial policy. On the other hand, we strive to find out the development paths of enterprises in epidemic crises or major social crises through research and exploration. And we hope that these measures would provide guidance for other enterprises' financing requirements, improve the financing capacities of small and micro-enterprises, promote the optimization and upgrading of the entire product market and achieve the high-quality development (Papadopoulos, Baltas and Balta, 2020) [4]. 


\section{CURRENT FINANCING SITUATIONS AND CASE OF SMALL AND MICRO-ENTERPRISES IN CHINA UNDER THE EPIDEMIC}

\subsection{Current financing situations of small and micro-enterprises}

\subsubsection{Narrow financing channels and high financing costs for small and micro-enterprises}

Enterprises founders had trouble accessing substantial amounts of capitals in the beginning, so the businesses they created were generally small and weak. Small-scale production and operation limits profitability and development of small and micro-enterprises, which in turn leads narrow financing channels and high costs to obtain loans. The small size and financing difficulties make it extremely difficult to create economies of scale, which become a vicious circle with long-term negative consequences. Although there are increasingly diverse financing approaches in the current economic environment, small and micro-enterprises are not the priority to carry out cooperation for financial institutions, which pursue profit maximization and financial deepening (Maier, 2016) [5]. The financing difficulties of enterprises have not improved, but rather have worsened to some extent. A large proportion of enterprises rely solely on endogenous financing to raise funds, and use a very small proportion of external financing. In addition, small and micro-enterprises are often at a disadvantage when cooperating with financial institutions, as their loan interest rates, service fees and guarantee fees are much higher than those of large enterprises.

Under this epidemic situation, the current predicament faced by small and micro-enterprises has deepened further. The biggest impact of the epidemic was the lack of market demand, and the original orders were indefinitely postponed or canceled, which resulted in the enterprises to make ends meet. They were at the periphery of the industrial chain and subjected to increase constraints. Labor costs for enterprises were increased substantially because of the restrictions on population movement. The increased costs to the enterprises also included expenditures of the necessary epidemic materials for the resumption of work and production. In addition, the external financing environment continued to tighten and deteriorate, such as severe fluctuations in the financial market, which put pressure on the enterprises to face liquidity difficulties. Table 1 reflects all the current difficulties faced by small and micro-enterprises, from which can be seen that the biggest dilemma is the lack of market demand. Besides, the difficulties cover overall cash flow constraints, shortage of raw material supplies, and untimely logistics.
Table 1. Difficulties faced by small and micro-enterprises during the epidemic and their proportion in the total number of enterprises

\begin{tabular}{|c|c|}
\hline Difficulties & Proportion \\
\hline Lack of market demand & $46.97 \%$ \\
\hline Overall cash flow constraints & $27.29 \%$ \\
\hline Shortage of raw material supplies & $25.94 \%$ \\
\hline Untimely logistics & $23.65 \%$ \\
\hline Difficulties in paying wages & $14.36 \%$ \\
\hline Pressure to repay loans & $11.95 \%$ \\
\hline $\begin{array}{c}\text { Difficulties in delivering orders due to } \\
\text { lack of productivity }\end{array}$ & $11.33 \%$ \\
\hline Other difficulties & $11.21 \%$ \\
\hline
\end{tabular}

Data source: Postal Savings Bank of China

\subsubsection{Imbalance in the allocation of financial resources, polarization of financing between listed and non-listed enterprises}

To a certain extent (i.e., in a short time), the financial resources of whole society are limited and scarce. If these resources are allocated by market, most of the capital will flow to the larger and more reputable enterprises, which leads to an imbalance in the allocation of financial resources. And it is difficult for non-listed enterprises to obtain sustainable funding, because they are relatively smaller and have fewer assets to pledge compared to listed enterprises, which results in a polarization of two types of enterprises when they access financing. In addition, due to the pressure of competition among enterprises in the same industry, the shortage of funds makes the enterprises' risk resistances are weak. Therefore, the financing between listed and unlisted companies is polarized. Even if there are government supports for small and micro-enterprises, the funds obtained through financing are less because of their weaknesses and insufficient competitive advantages.

Under this epidemic situation in early 2020, there were massive restrictions on the movement of people across the country. And the government has promulgated policies to resume work and production, but the policies have prioritized benefiting large enterprises involved in people's livelihoods. At the same time, large listed enterprises had channels and abilities to build online sales platform, which alleviated operational problems to a certain extent. But many small and micro-enterprises were already on the verges of bankruptcy after three-month shutdowns. Table 2 estimates the probable percentage change in the enterprises' annual operating incomes due to the epidemic. According to the data, we can see that only $9.33 \%$ of the country's small and micro-enterprises perform better than last year, and nearly $80 \%$ of enterprises' performances get significantly worse. This showed that micro and small-enterprises were at greater risks of bankruptcies, while receiving little policy helps. 
Table 2. Statistics on the possible changes in annual operating incomes due to epidemic

\begin{tabular}{|c|c|}
\hline Estimated operating incomes & Proportion \\
\hline$>10 \%$ & $2.5 \%$ \\
\hline$(0,10 \%]$ & $6.83 \%$ \\
\hline$(-10 \%, 0]$ & $27.58 \%$ \\
\hline$(-20 \%,-10 \%]$ & $29.21 \%$ \\
\hline$(-50 \%,-20 \%]$ & $17.43 \%$ \\
\hline$<-50 \%$ & $4.13 \%$ \\
\hline Unable to judge & $12.32 \%$ \\
\hline
\end{tabular}

Data source: Postal Savings Bank of China

\subsection{Financing Case}

HB Trading Company was established on 1 November 2018 with a registered capital of RMB 101 million, which located in Wuhan, Hubei Province. And this company operates primarily in supermarket retails, including fishery products, fresh meats, primary agricultural products, flowers, and so on. Because of the geographical location and the company's aquatic products, it has been severely negatively impacted during the epidemic. Through the field survey, we obtained the changes in the proportion of funding sources before and after the epidemic in $\mathrm{HB}$ Trading Company (Table 3).

From Table 3, it can be seen that after the outbreak of the epidemic, the enterprise mainly relies on its own funds $(31.96 \%)$, and the ratio of internal financing and private lending decreases by more than $60 \%$, while other financing sources through financial institutions don't change significantly. In fact, both at its early inception and post-epidemic, the company's reliance on its own internal fund-raising are high, at around 80 percent, but the epidemic exacerbates this level. In the current Chinese context, these problems are common in the development of the vast majority of micro and small-enterprises. In order to expand the scales of production, the enterprises' demands for loans from banks and other financial institutions are increasing, but the effects are not very significant. Therefore, it is difficult to get effective solutions to financing problems in the short term.

Table 3. Changes in the proportion of funding sources before and after the epidemic in HB Trading Company

\begin{tabular}{|c|c|c|c|}
\hline $\begin{array}{c}\text { Sources of } \\
\text { funding }\end{array}$ & $\begin{array}{c}\text { Early } \\
\text { inception }\end{array}$ & Post-epidemic & Changes \\
\hline Own funds & $62.04 \%$ & $81.87 \%$ & $19.83 \%$ \\
\hline $\begin{array}{c}\text { Internal } \\
\text { loans }\end{array}$ & $16.32 \%$ & $6.23 \%$ & $-10.09 \%$ \\
\hline $\begin{array}{c}\text { Private } \\
\text { loans }\end{array}$ & $15.20 \%$ & $5.76 \%$ & $-9.44 \%$ \\
\hline Bank loans & $3.04 \%$ & $2.90 \%$ & $-0.14 \%$ \\
\hline $\begin{array}{c}\text { Credit union } \\
\text { loans }\end{array}$ & $3.03 \%$ & $3.14 \%$ & $0.11 \%$ \\
\hline Other & $0.37 \%$ & $0.10 \%$ & $-0.27 \%$ \\
\hline \multicolumn{4}{|c|}{ Data source: Annual reports of company }
\end{tabular}

\section{MAIN CAUSES AND COUNTERMEASURES ON FINANCING DIFFICULTIES OF SMALL AND MICRO-ENTERPRISES}

\subsection{Main causes}

At present in China, the problems of over-reliance on internal financing and the difficulty of obtaining external financing are common to most small and micro-enterprises. They are increasing their demands for loans from banks and other financial institutions to expand production, but the results are not very significant. Therefore, it is difficult to solve financing problems effectively in a short term. While the epidemic increases financing difficulties of enterprises, it only worsens to a certain extent and is not the primary cause (Wuxiang Zhu, Ping Zhang, et al., 2020) [6]. The main causes of financing difficulties for small and micro-enterprises include the following.

\subsubsection{Small and micro-enterprises themselves, imperfect business management and financial systems}

Because of the early development of small and micro-enterprises prioritizes short-term survival and current profits without long-term business goals, there are weak links at the management level. Most enterprises are engaged in the primary processing of products, which are characterized by low profit, low cost, and low price. The enterprises, these vulnerable groups lack access to large-scale financing, so there is a strong financial exclusion when they cooperate with financial institutions.

During the epidemic situation of COVID-19, the shortage of raw materials has been needed for the enterprises' operation due to the inconvenience of transportation, which severely reduced the efficiency of production. Customers have reduced on a very large scale, which resulted in a lack of market demand. In addition, the enterprises' managers lacked capacities to deal with major risks such as the unexpected epidemic. In summary, these factors led to lower profits that were not even sufficient to meet the increased costs and further reduced their resilience.

\subsubsection{Government, inadequate financial service systems and cumbersome approval procedures}

While government support policies are shifting to the positive side, there are still constraints compared to the overall economic environment. Under the regulation of market liberalization, financial institutions such as banks, guarantee companies, insurance companies, and stock exchanges mostly serve listed companies and large enterprises, which leads to a complete polarization of the entire financial services system. Last but not the least, the 
redundant government agencies and the cumbersome credit approvals make the financing process harsh, time-consuming, and inefficient.

Under the epidemic, the government has introduced numbers of policies to support development of small and micro-enterprises to precisely promote the resumption of work and production. But the sheer size of enterprises in the overall market made competition fierce within the same industries. Limited preferential policies tended to favor relatively leading enterprises in the region, and most small and micro-enterprises did not enjoy the policies' dividends.

\subsubsection{Financial institutions, information asymmetries and limited financing capacities of local institutions}

The redundant credit system in the banks' investigation of information on small and micro-enterprises creates a barrier. And the enterprises' own inactions exacerbate the information asymmetries between them. Local financial institutions are geographically limited in the scope of their operations, such as small urban commercial banks and Rural Credit Cooperatives(RCC), which are generally located in rural areas or underdeveloped towns, where the standards of living are universally low. And these factors limit the abilities of financial institutions to raise capital and the financing of enterprises.

Financial conditions have contracted further, capital flows have become more conservative, and the entire market has been fraught with uncertainties during the epidemic. At the same time, smaller local financial institutions were experiencing operational difficulties due to shrinking business, which made it more difficult for small and micro-enterprises to obtain support from financial institutions.

\subsection{Countermeasures}

Based on the above research, we find that the main causes of financing difficulties of small and micro-enterprises are not only their own shortcomings but also the negative influences of government and financial institutions. Therefore, the formulation of solutions should not be one-sided, but should be based on the above three perspectives.

\subsubsection{Small and micro-enterprises themselves, establishing own brands, improving management and credit systems}

Small and micro-enterprises should strictly control the qualities in the production, and gradually establish their own brands, which can eventually feed the development of enterprises through high-quality brands, these intangible assets. The enterprises also need to improve the management system internally, change the employment system, and change the hiring criteria from affinity to talent. And then they can establish long-term partnerships with accounting firms or other institutions to hire professionals to regularly audit their accounts, and these staffs could provide professional guidance on irregularities and irrationalities. At the same time, external accountants can also play good supervisory roles in enhancing the binding and credibility of enterprises. Furthermore, when working with banks and other financial institutions, the enterprises can also hire professional accountants to negotiate on behalf, because these workers are better acquainted with the credit approval processes, workflows, preparation materials, and considerations than internal employees. These measures can effectively reduce the costs of time and the costs of corporate reform, which can have the effect of saving money and promote the development of enterprises.

Under the epidemic, the small and micro-enterprises should pay more attention to their own brands building, strictly abide by national health and safety standards, and take initiatives to undertake the necessary epidemic supplies and services for the health of employees and customers. The enterprises' managers should actively improve their abilities to deal with major risks and develop appropriate special management systems to ensure that safe conditions can smoothly achieve the resumption of work and efficient production and operation.

\subsubsection{Government, improving the financial service systems and increasing policy supports}

As for the recommendations of the government, there are two avenues for improvement. On the one hand, the government should improve the financial services system, establish a government-led information service sharing mechanism with financial institutions and small and micro-enterprises. The government needs to speed up the construction of an independent legal system for the enterprises, intensify its efforts to enact relevant laws so that they are legally enforceable, and then clearly regulate the rights and obligations of small and micro-enterprises. At the same time, it should strengthen the effectiveness of supervision to prevent enterprises from exploiting the legal loopholes. On the other hand, the government can strengthen financial subsidies and establish diversified supports, such as tax and fee reductions, technical assistances, and decentralization of administration. The government could learn from the unique policy support system of the United States and establish a policy-based financial institution, the Small and Micro-enterprises Administration, to indirectly enhance the financing capacities of enterprises. And it can set up a special financial assistance fund to integrate the current scattered funds, and it will provide precise assistances to qualified small and micro-enterprises to implement a standard whenever possible, which is one enterprise, one policy.

The government is supposed to actively guide small and micro-enterprises to comply with regulations and operate 
within the laws under the epidemic. It should further implement the policy called tax and fee reductions and strive for $100 \%$ full coverage of inclusive finance supports for enterprises. In addition, the government could improve the public system of telecommuting, streamline service procedures, and increase the efficiency and capacity of targeted services.

\subsubsection{Financial institutions, establishing two-way information disclosure mechanisms and innovating financing methods}

First, the small and micro-enterprises should raise their own awareness of integrity, take initiative to disclose the business and financial information. And financial institutions completely screen and select high-quality customers and actively form cooperative relationships with them, which can further mitigate the overall financial market information asymmetries. Second, the small and micro-enterprises could access small loans through founding local financial institutions, using new Internet technologies and innovating financing methods. Finally, further streamlining procedures and saving costs address the concerns of enterprises whose lack of capital may lead to a break in the financial chains, such as establishment of local venture capital institutions to provide unsecured loans to small and micro-enterprises engaged in high-technology industries, or direct contributions in exchange for corporate shares.

The further boom in online trading will be driven by logistical constraints during the epidemic. Financial institutions can make use of the Internet, big data, cloud computing, 5G and other new network technologies to establish an online mutual aid platform for small and micro-enterprises to strengthen business integration among them, while the government provides policy supports and supervises the operation of the platform, so that it can play an effective role in capital saving, information sharing and interbank lending.

\section{CONCLUSION}

The small and micro-enterprises' financing difficulties seriously constrain the sustainable development of themselves, and the existences of these problems have a long-term character, so the relevant works to alleviate or even solve the financing difficulties will be a long battle. The impact of the epidemic situation of COVID-19 has exacerbated the problems faced by enterprises, but the epidemic itself was not the root cause of the financing difficulties of companies. Problems arise as the result of combination of internal and external factors, consequently, it's necessary for the small and micro-enterprises, government and financial institutions to trust each other, deepen cooperation and make progress together. The enterprises introduce complete incentive systems for talents and financial management systems to improve their credibilities and business levels. With the supports of government policies, the small and micro-enterprises will reach a stable strategic partnership with financial institutions, and they will eventually be able to effectively solve the problems of financing difficulties and achieve better and faster development.

\section{ACKNOWLEDGMENT}

This work was supported by Hubei Rural Development Research Center and Chinese Social Science Foundation with grant number 15BJY092.

\section{REFERENCES}

[1] M. Ayyagari, T. Beck, and A. Demirguc-Kunt, "Small and medium enterprises across the globe," Small Business Economics, vol. 29, January 2007, pp. 415-434

DOI:https://doi.org/10.1007/s11187-006-9002-5

[2] R. Cull, and L.C. Xu, "Institutions, ownership, and finance: the determinants of profit reinvestment among Chinese firms," Journal of Financial Economics, vol. 77, July 2005, pp. 117-146.

DOI:https://doi.org/10.1016/j.jfineco.2004.05.010

[3] F. Sulong, M. Sulaiman, and M.A. Norhayati, "Material Flow Cost Accounting (MFCA) enablers and barriers: the case of a Malaysian small and medium-sized enterprise (SME)," Journal of Cleaner Production, vol. 108, December 2015, pp. 1365-1374. DOI: https://doi.org/10.1016/j.jclepro.2014.08.038

[4] T. Papadopoulos, K.N. Baltas, and M.E. Balta, "The use of digital technologies by small and medium enterprises during COVID-19: Implications for theory and practice," International Journal of Information Management, vol. 102192, December 2020. DOI:https://doi.org/10.1016/j.ijinfomgt.2020.102192

[5] E. Maier, "Supply and demand on crowdlending platforms: connecting small and medium-sized enterprise borrowers and consumer investors," Journal of Retailing and Consumer Services, vol. 33, November 2016, pp. 143-153.

DOI:https://doi.org/10.1016/j.jretconser.2016.08.004

[6] Wuxiang Zhu, Ping Zhang, Pengfei Li, and Ziyang Wang, "Firm crisis, government support and policy efficiency under the epidemic shock: evidence from two waves of questionnaire on SMEs," Management World, vol. 36, April 2020, pp. 13-26.

DOI:https://doi.org/10.19744/j.cnki.11-1235/f.2020.004 9 (In Chinese) 